Journal of Aafiyah Health Research (JAHR)

$P-I S S N$ : 2722-4929 \& E-ISSN : 2722-4945

Published by Postgraduate Program in Public health, Muslim University of Indonesia

\title{
Problem Focus Coping Pada Narapidana Seumur Hidup Di Lembaga Pemasyarakatan Kelas I Makassar
}

\author{
Arniati Santi ${ }^{1}$, Andi Asrina ${ }^{2}$, Andi Nurlinda ${ }^{3}$ \\ ${ }^{1}$ Lembaga Pemasyarakatan Kelas I Makassar \\ ${ }^{2,3}$ Pascasarjana Kesehatan Masyarakat, Universitas Muslim Indonesia Makassar
}

Email: arniati1977@gmail.com

\begin{abstract}
Background: Individuals are required to make adjustments to life in the Penitentiary in a very long period of time even during his life. Adjustment to the environment in prison can lead to various psychological disturbances to prisoners, especially in prisoners sentenced to life imprisonment due to new situations, meeting people with different backgrounds and with different cases as well. To be able to cope with and adapt to face emotional stress in prison, residents assisted with life sentences need coping. Inability of prisoners to manage their emotions so that things can happen that are not desirable until a suicide attempt to commit suicide. Effective coping behaviors will produce adaptation, so that emotional stresses such as anxiety, stress, and depression will be reduced and overcome. Meanwhile, if ineffective coping behavior can lead to maladaptive (adaptation failure) which will worsen one's health condition. Therefore, it is important to analyze the reasons behind coping behavior by inmates for life. Method: this type of research is qualitative with a qualitative quasi approach on subjects with a sentence of 8 years and below and able to communicate well using primary data of 4 main informants. Data collection techniques used were interviews, observation and documentation. Analysis of the data used is the analysis of taxonomy. Test the validity of the data in this study by using Triangulation namely triangulation of sources, techniques and time. Results: research shows that lifetime inmates use different coping strategies in dealing with a stress that occurs while in prison, this is caused by internal and external factors. Conclusion: Coping strategies used by life inmates are Problem focused coping, namely active coping, planning, and using instrumental support and behavioral disengagement.
\end{abstract}

Keywords: Problem focused Coping, Lifetime inmates

\section{ABSTRAK}


Latar belakang: Menjadi narapidana merupakan hal yang sangat sulit dan sesuatu yang tidak menyenangkan karena harus menjalani kehidupan di Lembaga Pemasyarakatan, apalagi narapidana hukuman seumur hidup. Individu dituntut melakukan penyesuaian kehidupan di dalam Lembaga Pemasyarakatan dalam jangka waktu yang sangat panjang bahkan selama hidupnya. Penyesuaian diri dengan lingkungan di dalam penjara dapat memunculkan berbagai gangguan psikologis terhadap narapidana, terutama pada narapidana hukuman seumur hidup disebabkan karena situasi baru, bertemu dengan orang-orang dengan latar belakang yang berbeda-beda dan dengan kasus yang berbedabeda pula. Untuk dapat mengatasi dan menyesuaikan diri dalam menghadapi tekanan emosional di dalam Lapas maka narapidana hukuman seumur hidup membutuhkan koping. Ketidakmampuan narapidana dalam mengelola emosionalnya sehingga dapat terjadi hal-hal yang tidak diinginkan sampai percobaan bunuh diri hingga melakukan bunuh diri. Perilaku koping yang efektif akan menghasilkan adaptasi, sehingga tekanan emosional seperti cemas, stres, dan depresi akan berkurang dan diatasi. Sedangkan apabila perilaku koping tidak efektif dapat mengakibatkan maladaptif (kegagalan adaptasi) yang akan memperburuk kondisi kesehatan seseorang. Oleh karena itu, penting untuk menganalisa alasan dibalik perilaku koping yang dilakukan narapidana seumur hidup. Metode: jenis penelitian ini adalah kualitatif dengan pendekatan Quasi kualitatif pada subjek dengan masa hukuman yang sudah dijalani 8 tahun kebawah dan mampu berkomunikasi dengan baik dengan menggunakan data primer sebanyak 4 informan utama. Teknik pengumpulan data yang dipakai adalah wawancara, observasi dan dokumentasi. Analisis data yang digunakan adalah analisis Toksonomi. Uji keabsahan data dalam penelitian ini dengan menggunakan Triangulasi yaitu Triangulasi sumber, teknik dan waktu. Hasil: penelitian menunjukan bahwa narapidana seumur hidup menggunakan strategi koping yang berbeda-beda dalam menghadapi suatu tekanan dan masalah stres yang terjadi selama berada di Lembaga Pemasyarakatan, hal ini disebabkan oleh faktor internal dan eksternal. Kesimpulan: strategi koping yang digunakan oleh narapidana seumur hidup adalah Problem focused coping yaitu Active coping, planning, using instrumental support dan behavioral disengagement.

Kata kunci: Problem focused coping, Narapidana seumur hidup

\section{PENDAHULUAN}

Narapidana hukuman seumur hidup ini selama di Lapas mengalami tekanan hidup yang disebabkan oleh berbagai faktor. Tekanan hidup yang dirasakan oleh narapidana hukuman seumur hidup, memunculkan berbagai gangguan kesehatan baik fisik maupun psikologis. Begitupun di Lembaga Pemasyarakatan Kelas I Makassar dihuni oleh Narapidana sebanyak 979 orang dengan daya tampung seharusnya 740 orang, ini berarti bahwa Over
Kapasitas sekitar 32,3\%. Dari jumlah keseluruhan narapidana yang ada di Lapas kelas I Makassar terdapat narapidana dengan hukuman seumur hidup sebanyak 21 orang yang merupakan populasi kedua terkecil setelah narapidana hukuman mati dari semua kelompok narapidana yang ada di Lembaga Pemasyarakatan (1).

Untuk dapat mengatasi dan menyesuaikan diri dalam menghadapi tekanan emosional di dalam Lapas maka narapidana hukuman seumur hidup membutuhkan koping. 
Ketidakmampuan narapidana dalam mengelola emosionalnya sehingga dapat terjadi hal-hal yang tidak diinginkan sampai percobaan bunuh diri hingga melakukan bunuh diri (2).

Perilaku koping penting dilakukan dalam mengatasi tekanan/stres yang dialami. Untuk mengatasi masalah, setiap orang akan memperlihatkan perilaku koping yang berbeda-beda. Hal ini tergantung pada penilaian dan sumber daya yang dimiliki. Pengalaman hidup dan perasaan narapidana hukuman seumur hidup yang berada di Lapas belum banyak tereksplorasi. Penting untuk mengungkapkan dan memahami pengalaman dan perilaku koping narapidana hukuman seumur hidup. Hal ini akan membantu untuk mengurangi dan mengatasi rangkaian masalah kesehatan yang terjadi pada narapidana hukuman seumur hidup di Lapas (3).

Perilaku koping yang efektif akan menghasilkan adaptasi, sehingga tekanan emosional seperti cemas, stres,dan depresi akan berkurang dan diatasi. Sedangkan apabila perilaku koping tidak efektif dapat mengakibatkan maladaptif (kegagalan adaptasi) yang akan memperburuk kondisi kesehatan seseorang . Oleh karena itu, penting untuk menganalisa alasan dibalik perilaku koping yang dilakukan narapidana seumur hidup (4).

Meskipun sistem Pemasyarakatan yang berlaku sekarang ini sudah mengalami banyak perubahan dan sudah dianggap baik, tetapi tetap saja memunculkan banyak masalah seperti stigma tentang penjara yang menimbulkan perasaan takut, cemas dan stress bagi narapidana, meskipun istilah penjara telah berganti menjadi Lembaga Pemasyarakatan. secara konseptual dan historis sangatlah berbeda dengan apa yang berlaku dalam sistem kepenjaraan.

Berdasarkan penelitian Thomas Helmesdan Richard Rahe (1987), berada dalam penjara dapat mengakibatkan stres dengan skala yang sama ketika seseorang kehilangan anggota keluarganya (Goncalves \& Others 2016). Selanjutnya dalam kondisi stres yang dirasakan mengakibatkan individu akan mengalami depresi atau kecemasan yang berkepanjangan, menurut Tailor (1953) Kecemasan adalah suatu perasaan subyektif mengenai ketegangan mental yang menggelisahkan sebagai reaksi umum dari ketidakmampuan mengatasi suatu masalah atau tidak adanya rasa aman. Seseorang akan menderita kecemasan manakala yang bersangkutan tidak mampu mengatasi stressor psikososial yang dihadapinya (5).

Narapidana seumur hidup yang mengalami stress dan kecemasan dalam menghadapi kehidupan di Lembaga Pemasyarakatan, gangguan yang selalu muncul pada saat berada didalam penjara antara cemas yang berlebihan, merasa sedih dan depresi, merasa hidup tidak berharga serta sulit untuk antusias terhadap banyak hal. Oleh karena itu narapidana yang ada di lembaga pemasyarakatan membutuhkan kemampuan dan dukungan agar dapat mengurangi dan mengatasi kecemasan tersebut.

Cara ataupun upaya yang dilakukan oleh individu menangani kecemasan disebut sebagai koping. Menurut Lazarus dan Folkman (1984), koping didefenisikan sebagai upaya kognitif dan perilaku yang akan terus berubah agar individu mengelola tuntutan eksternal dan atau tuntutan internal yang dinilai melebihi kemampuannya. Selain itu menurut Stuart (1998), koping adalah upaya yang dilakukan untuk mengatasi tekanan baik yang berasal dari diri maupun lingkungan sehingga menghasilkan keringanan dan keseimbangan (6). 
Secara alamiah baik disadari ataupun tidak, individu menggunakan berbagai perilaku atau strategi koping dalam menghadapi stressor (Rasmun, 2004). Secara garis besar ada dua strategi koping yang digunakan individu yaitu problem focused coping dan emotion focused coping. Problem focused coping adalah cara koping yang berfokus pada penyelesaian masalah sementara Emotion focused coping adalah cara koping yang berfokus pada emosi. Dalam upaya mengatasi masalah, metode yang digunakan biasanya melibatkan kombinasi dari problem focused coping dan emotional focused coping .

Strategi koping yang digunakan oleh narapidana seumur hidup akan membantunya dalam menyesuaikan diri dengan tanggungjawab dan tekanan yang muncul melalui perilaku tertentu. Perilaku yang muncul dapat berupa respon tindakan negatif namun dapat juga berupa respon tindakan positif. Respon tindakan yang berbeda-beda dari narapidana sangat tergantung dari proses penilaiannya terhadap kondisi yang dihadapinya (7).

Narapidana seumur hidup selama di Lembaga Pemasyarakatan mengalami berbagai tekanan hidup yang disebabkan oleh berbagai stressor seperti hilangnya kebebasan, berpisah dari keluarga, kurangnya waktu besukan, kepadatan penghuni, kurangnya dukungan sosial, dan lamanya pidana yang harus dijalani yakni seumur hidup. Ganster (dalam Nur \& Shanti,2011) menyebutkan bahwa salah satu faktor eksternal yang dapat meminimalisir stress adalah adanya dukungan sosial dari lingkungan sekitarnya.

Hal ini dikarenakan dukungan sosial menunjukkan hubungan interpersonal yang melindungi seseorang maupun kelompok dari perilaku negatif selain untuk mencari nasehat, bantuan maupun informasi guna menyelesaikan permasalahan yang dihadapinya (8).

\section{METODE PENELITIAN}

Penelitian ini akan dilaksanakan di Lembaga Pemasyarakatan (Lapas) Kelas I Makassar jalan Sultan Alauddin, Provinsi Sulawesi Selatan pada bulan Maret sampai Mei tahun 2020.

Penelitian ini menggunakan metode penelitian kualitatif dengan pendekatan Quasi Kualitatif, dengan maksud untuk mengeksplorasi mengenai strategi koping pada narapidana hukuman seumur hidup di Lembaga Pemasyarakatan kelas I Makassar dengan cara Observasi, Wawancara mendalam dan Dokumentasi secara terus-menerus selama penelitian berlangsung. Jumlah informan dalam penelitian ini sebanyak 4 orang informan utama, 2 informan pendukung dan 1 informan kunci.

Dalam penelitian ini pengumpulan data dilakukan melalui beberapa metode : Observasi atau studi lapangan, Wawancara mendalam (indept interview) dan Dokumentasi dengan Uji keabsahan data menggunakan Triangulasi yaitu Triangulasi Sumber untuk mencocokkan dan membandingkan data yang diperoleh dari sumber informasi yang satu dengan sumber informasi yang lainnya yaitu antara informan kunci, informan pendukung dan informan biasa, Triangulasi tehnik dilakukan untuk mengcross check data yang sudah didapatkan melalui Observasi, Wawancara mendalam dan Dokumentasi selama penelitian berlangsung dan Triangulasi waktu dilakukan untuk mendapatkan informasi dengan cara membandingkan data yang sudah didapatkan dengan kembali melakukan observasi, wawancara 
mendalam dan dokumentasi pada waktu dan situasi yang berbeda.

\section{HASIL}

Penelitian yang dilaksanakan terhadap 4 infoman utama dengan subjek narapidana seumur hidup semua berjenis kelamin laki-laki yang dilaksanakan pada bulan Maret-Mei 2020 di Lembaga Pemasyarakatan Kelas I Makassar di dapat infomasi berbagai macam proses koping yang lakukan oleh narapidana seumur hidup baik secara sadar maupun tidak sadar yang mereka lakukan merupakan strategi koping .

\section{Problem Focused Coping}

1. Active coping

Sebagaimana yang diungkapkan oleh informan.

"jadi sekarang kalau ada masalah sama teman lebih baik saya diam, atau langsung saya tegur bicara baik-baik, langsung diselesaikan supaya tidak berlarut-larut supaya tidak ada beban, seperti kemarin ada salah paham karena jadwal tugas membersihkan di kamar tapi langsung diselesaikan saat itu juga jadi tidak berlarut-larut, dulu kalau ada yang singgung perasaanku, langsung saya emosi baru mau pukul itu orang, biasa juga saya langsung tinggalkan baru pergi menyendiri. Kalau ada orang yang cerita-cerita biasa juga tersinggungka seperti rasanya saya yang na ceritai,Kalau sekarang sudah tidak lagi, biar lagi saya yang na ceritai lebih baik saya diam dan sabar, dia sendiri yang berdosa,jadi sekarang kalau ada masalah sama teman lebih baik saya diam"'SBH 45 tahun, 23 Maret, jam 10:15 WITA).

2. Planning

Sebagaimana yang dikatakan oleh informan "saya masih merasa normal, tidak pernah berbuat yang aneh-aneh selama disini karena selalu ikut aturan yang ada, masih bisa ketawa-ketawa dan masih mempunyai harapan untuk merubah hukuman meskipun itu sangat kecil kemungkinannya" (RM 32 tahun, 20 Maret,jam 09:00 WITA).

\section{Using Instrumental Support}

Sesuai yang diungkapkan oleh informan bahwa:

"Kalau sudahka telpon orang tuaku lega lagi perasaanku jadi tenang karena dapatki lagi siraman rohani hehehe, pasti dapat nasehat dengan kata-kata sabarko nak, jalanimi saja, jangan lupa shalat"(MAB 28 tahun,19 Maret,jam 09:35 WITA).

\section{Behavioral Disengagement}

Seperti yang dikatakan oleh informan "setelah saya berada di sini semua saya jalani dengan pasrah dan menyesali apa yang telah saya lakukan, hari-hari saya lalui di penjara harus saya hadapi dengan pasrah, karena sebenarnya saya itu orangnya gampang sekali emosional, mungkin inilah akibatnya" $(M, 30$ tahun,24 Maret,jam 10:10 WITA ).

\section{PEMBAHASAN}

Berdasarkan infomasi yang didapatkan baik secara langsung dari informan dan pengamatan yang dilakukan peneliti terhadap respon yang diberikan pada saat wawancara maupun selama penelitian yaitu peneliti mencoba menggunakan teknik observasi kepada narapidana yang pada saat itu menolak untuk dilakukan wawancara. Informan yang didalami hanya 4 narapidana 
seumur hidup karena menjawab pertanyaan dengan baik dan lebih komunikatif. Berdasarkan hasil penelitian didapatkan :

\section{Problem Focused Coping}

\section{Active Coping}

Narapidana seumur hidup yang melakukan dimensi ini langsung menuju ke sumber masalah dan menyelesaikannya seperti ketika harga diri keluarganya diinjak-injak dan dihina maka dia membunuh tanpa memikirkan konsekuensinya. Ketika cara penyelesaian masalahnya ternyata berdampak buruk maka dia segera memperbaiki diri, begitupun didalam penjara ketika ada orang yang menyinggung perasaannya maka dia langsung menuju ke orang itu lalu berusaha mengatasi masalahnya dengan jalan memukul, hal ini sesuai yang dikatakan oleh informan ketika dilakukan penelitian. Selain itu, diungkapkan pula kepada peneliti bahwa setiap ada sesuatu atau orang lain yang dianggap mengganggu, narapidana langsung mendatangi dan menyelesaikan masalahnya saat itu juga.

Hal yang dilakukan oleh narapidana seumur hidup ini termasuk didalam Active Coping seperti yang dinyatakan oleh Taylor (2003) bahwa Active Coping adalah individu memulai tindakan langsung, meningkatkan usaha-usaha untuk menghadapi masalah dan berusaha melakukan upaya untuk mengatasi masalah secara bertahap. Coping yang dilakukan oleh narapidana dengan cara langsung memukul atau membunuh juga cendrung merupakan tindakan frontal dan agresif, hal ini sejalan dengan teori Lazarus dan Folkman (1984) yang menyatakan bahwa salah satu Problem Focused Coping adalah melakukan tindakan frontal (konfrontasi) yang agresif.
Coping dengan cara frontal yang konfrontatif yang dilakukan oleh narapidana seumur hidup juga merupakan coping yang maladaptive yaitu reaksi seseorang yang tidak sesuai. Hal ini sejalan dengan hasil penelitian yang ditemukan oleh Agresia, Abdul Halim \& Idawati Manurung (2014) yang menyatakan bahwa narapidana yang memiliki coping Maladaptif (sebanyak 48,49\%) (9).

\section{Planning}

Berdasarkan dimensi lainnya yang dilakukan oleh narapidana seumur dalam menghadapi stressor yang dihadapi yaitu dengan berpikir dan melakukan rencana-rencana tentang apa yang akan dilakukan kedepannya setelah menjalani hari-harinya didalam penjara agar mampu menghadapi situasi stress yang ada. Tindakan-tindakan yang dilakukan tersebut dianggap mampu membantunya keluar dari situasi yang sangat menekan misalnya dengan melakukan aktifitas rutin yang berguna dengan melayani dan merawat orang yang sakit dengan alasan karena secara fisik mereka tidak mampu memenuhi kebutuhannya sendiri, hal ini sesuai dengan hasil observasi yang dilakukan oleh peneliti dan pernyataan yang diungkapkan oleh narapidana seumur hidup bahwa dia akan merawat orang sakit yang sudah berusia lanjut seperti merawat orang tuanya sendiri.

Aktifitas rutin yang dilakukan oleh narapidana seumur hidup ini benar-benar berguna dalam mengisi waktu yang dirasa sangat panjang dan tak berujung. Tindakan ini ini dilakukan karena mereka menganggap tidak ada lagi kegiatan lain yang bisa dilakukan didalam penjara, oleh karena itu mereka harus berpikir dan mempunyai rencana dalam mengatasi dan menghadapi masalahnya. Hal ini sejalan dengan hasil 
penelitian yang ditemukan oleh Karim dan Mufti Maulid Ati (2016) yang menyatakan bahwa Problem Focused Coping yang digunakan oleh narapidana berbeda-beda termasuk didalamnya Planning.

Hal yang dilakukan oleh narapidana seumur hidup ini termasuk didalam Planning seperti yang dinyatakan oleh Taylor (2003) bahwa Planning yaitu berpikir cara menghadapi stresor. Planning atau perencanaan meliputi mengajukan strategi tindakan, berpikir mengenai langkah yang harus diambi dan bagaimana memilih cara terbaik dalam mengatasi masalah. (10)

\section{Using Instrumental Support}

Dimensi yang dilakukan oleh narapidana seumur hidup bervariasi termasuk ketika narapidana merasa kehilangan sosok orang yang mampu memberikan solusi ketika dalam situasi yang tidak menyenangkan, narapidana tersebut akan mencari orang lain yang bisa membantunya menghadapi situasi dan masalah yang dihadapinya. Seperti yang dilakukan oleh salah satu narapidana seumur hidup, ketika baru berada di Lembaga Pemasyarakatan menunjukkan respon yang secara fisiologis seperti sakit kepala, pusing dan susah tidur karena memikirkan orang-orang yang selama ini dekat dengannya dan selalu memberinya nasehat ketika sedang mengalami masalah.

Berdasarkan hasil penelitian bahwa narapidana seumur hidup mengatakan sering memanfaatkan wartel yang disiapkan oleh Lapas pada bagian pembinaan untuk menelepon orang tuanya hanya untuk mendengarkan nasehat yang selama ini selalu didapatkan ketika masih berada diluar, hal ini juga dibenarkan oleh pegawai Lembaga Pemasyarakatan dalam hal ini pembina blok yang mengatakan bahwa narapidana seumur hidup sering meminta nasehat ketika dalam kondisi yang tertekan atau tidak menyenangkan. Problem focused coping yang digunakan oleh narapidana pidana seumur hidup adalah Using Instrumental Support. Hal ini sejalan dengan hasil penelitian yang ditemukan oleh Nur Fazliney Shuhada Shuhaimi, Syakirah Hamizi \& Salmi Razali (2018) yang menyatakan bahwa narapidana perempuan yang berada di penjara menggambarkan berbagai pola dukungan yang mereka terima dari staf di penjara. Hasil penelitian lain yang hampir sama ditemukan oleh Anita Rohman (2018) bahwa dinamika koping stres pada narapidana pengguna narkoba berbeda-beda.(11)

\section{Behavioral Disengagement}

Berdasarkan hasil wawancara yang dilakukan oleh peneliti menemukan bahwa koping yang dilakukan oleh narapidana seumur hidup ada yang memulai dari reaksi terhadap sumbersumber stres yang ditunjukkan dengan respon stres dengan menyendiri, begitu pula jika di tanya tentang keluarga dan masalahnya, hanya menjawab dengan singkat dan tersenyum. Narapidana tersebut menuturkan bahwa dia memang jarang bicara kepada orang lain, narapidana juga tidak berusaha mencari solusi dan melakukan usaha yang dapat mengurangi stres yang dihadapinya, akan tetapi cendrung menyerah dan pasrah.

Dimensi yang sama juga dilakukan oleh narapidana seumur hidup ketika baru masuk ke Lapas kondisi kesehatannya masih baik, akan tetapi saat ini jatuh sakit dan mengharuskannya di rawat karena sangat sulit berjalan. Sejak pertama divonis hukuman seumur hidup langsung tak sadarkan diri, dia membayangkan hukuman seumur hidup 
yang akan dijalani di usianya yang sudah tua dan sakit-sakitan akan

tetapi tidak banyak yang bisa dilakukan dengan kondisi yang dialaminya sekarang selain dengan cara pasrah dan berserah kepada Allah. Hal tersebut menunjukkan bahwa narapidana seumur hidup ini melakukan Problem Focused Coping yaitu Behavioral Disengagement.

Berdasarkan hasil penelitian dan analisa yang dilakukan oleh peneliti ditemukan bahwa narapidana seumur hidup menggunakan Problem Focused Coping dimensi Behavioral Disengegement yaitu individu mengurangi usaha dalam menghadapi situasi yang menimbulkan stres bahkan menyerah atau tidak melakukan apapun terhadap sumber stres tersebut sesuai hasil penelitian yang dilakukan oleh Anita Rohman (2018) tentang sumber-sumber stres yang dimunculkan secara internal dan eksternal.(12)

Tabel 1. Data Informan

\begin{tabular}{|c|c|c|c|c|c|}
\hline No & $\begin{array}{c}\text { Inisia } \\
\mathbf{l}\end{array}$ & Jenis Kelamin & $\begin{array}{c}\text { Usia } \\
\text { (Thn) }\end{array}$ & $\begin{array}{c}\text { Pendidika } \\
\mathbf{n}\end{array}$ & Keterangan \\
\hline 1 & MAB & Laki-laki & 28 thn & SMA & Informan Utama \\
\hline 2 & M & Laki-laki & 30 thn & SD & Informan Utama \\
\hline 3 & SBH & Laki-laki & 45 thn & SD & Informan Utama \\
\hline 4 & RM & Laki-laki & 32 thn & T.Sekolah & Informan Utama \\
\hline
\end{tabular}

\section{UCAPAN TERIMA KASIH}

Penulis ingin menyampaikan ucapan terima kasih kepada pembimbing, Lembaga Pemasyarakatan Kelas I Makassar serta semua informan penelitian yang telah bersedia berpartisipasi dalam memberikan informasi tanpa paksaan dan tanpa menuntut imbalan apapun.

\section{KESIMPULAN}

Terkait dengan Problem focused coping yang digunakan oleh narapidana pidana seumur hidup dalam penelitian ini adalah active coping seperti

memperbaiki diri dan menyelesaikan permasalahan, planning seperti tidak berbuat yang aneh dan mengikuti aturan serta membangun harapan untuk merubah hukuman, using instrumental support seperti mencari nasehat, mencari dukungan keluarga atau teman dan behavional disengagement yaitu menyendiri dan jarang berbicara, bersikap pasrah dan berserah diri kepada Allah SWT. problem focus coping yang digunakan oleh narapidana seumur hidup dalam penelitian ini berbeda-beda tetapi didalamnya termasuk planning. Problem focused coping yang dilakukan oleh narapidana seumur hidup adalah active coping dan planning yang berarti bahwa narapidana menggunakan cara ini sebagai cara-cara yang konstruktif dan adaptif untuk menghadapi masalah. Sedangkan problem focused coping lainnya yang digunakan oleh narapidana pidana seumur hidup dalam penelitian ini adalah melakukan tindakan frontal yang agresif. Hal ini menunjukkan bahwa narapidana melakukan coping maladaptif. Tindakan frontal (konfrontatif) yang agresif yang dilakukan oleh narapidana pidana semur 
hidup juga berarti bahwa mereka cenderung terlibat dalam kekerasan.

\section{DAFTAR PUSTAKA}

1. Agnesia, A., Halim, A., \& Manurung, I. 2014. Mekanisme Koping narapidana Kasus Narkoba yang menjalani Vonis Masa Hukuman di Lembaga Pemasyarakatan. Jurnal Keperawatan, Vol X, No. 1.

2. Aljanata Gusti Patria Nagara. Strategi coping stress pada narapidana remaja di Lapas anak Kelas IA Kutoarjo.(2017)

3. Atabay, T. Panduan Tentang Strategi untuk Mengurangi Kepadatan dalam Penjara. Wina: United Nations Office Drug and Crime (UNODC);2013.

4. Azizah, L. M., Zainuri, I., \& Akbar, A. Buku Ajar Keperawatan Kesehatan Jiwa. Yogyakarta: Indomedia Pustaka; 2016.(6)

5. Anita Rohman , 2018. Dinamika coping stress pada narapidana pengguna narkoba di Lapas.

6. Ann Marie Rocheleau . Ways Of Coping And In Prison Violence;2015.

7. Bungin, B. Metode Penelitian Kualitatif: Aktualisasi Metodelogis ke Arah Ragam Varian Kontemporer, Jakarta: Pustaka Pelajar; 2015.

8. Direktorat Jenderal Pemasyarakatan (Dirjenpas). Sistem Database Pemasyarakatan. http://smslap.ditjenpas.go.id/public. $\underline{(2019)}$

9. Green, J. and Thorogood, N. Qualitative Methods for Health Research. Sage;2013(8)

10. Gero Sabrina, Batbual Bringiwati, Perempuan yang berada di Lapas perlu Mekanisma Koping Efektif.(2016)
11. Hawari, D. Manajemen Stres Cemas dan Depresi. Edisi 2. Jakarta: Balai penerbit FKUI;2006.(2):11

12. Hendriani, W. Resiliensi Psikologis Sebuah Pengantar. Jakarta: Prenadamedia Group;2008

13. Ilmi, Z.M. 2017. Pengaruh Relaksasi Otot Progresif Terhadap Tingkat Stres Narapidana Wanita di Lapas Kelas II A Jember. E-Journal Pustaka Kesehatan, 5(3), 497-504

14. J.Maurus , 2018. Coping With Depression Jangan mau kalah dari Depresi

Khasan, M., \& Sujoko. Perilaku Koping Waria. Jurnal Sains Psikologi, Jilid 7, Nomor 1, 99-106 : Surakarta(2018)(3):4

15. Kholid, A. 2015. Promosi Kesehatan dengan Pendekatan Teori Perilaku, Media, dan Aplikasinya. Jakarta: Rajawali Pers.

16. Karim, Multi Maulid Ati. Problen Focused Coping pada narapidana tervonis Seumur Hidup di Lapas Kedungpane Kelas Semarang.(2016)

17. Latifah, M. 2019. Overcrowded pada Rumah Tahanan dan Lembaga Pemasyarakatan di Indonesia : Dampak dan Solusinya. Pusat Penelitian Badan Keahlian DPR RI1-6

18. Lazarus, R. S., \& Folkman, S. 1984. Stres, Appraisal and Coping. New York: Springer Publishing Company.

19. Lembaga Pemasyarakatan Kelas I Makassar. Laporan Poliklinik Lapas.(2019)(1)

20. Mohammad Khasan, Sujoko. (2018). Perilaku koping pada waria

21. Mu'jizatullah, Waode Sitti;. (2019). Pengaruh Penyesuaian Diri dan Dukungan Sosial Terhadap Stres pada Narapidana Pemasyarakatan Wanita (Di Rutan Kelas IIB 
Balikpapan). Psikoborneo, Volume 7, 340-352.

22. Nuria, M. W., Handayani, P. K., \& Rahmawati, E. I. 2016. Perbedaan Tingkat Stres Narapidana di Lembaga Pemasyarakatan Kelas IIA Jember ditinjau dari Lama Vonis. Repository. Unmuhjember, 1-10.

23. Palifiana, D. A., \& Jati, R. K. 2018. Hubungan Antara Tingkat stres dengan Kualitas Tidur pada Narapidana di Lembaga Pemasyarakatan Klas IIA Yogyakarta. Media Ilmu Kesehatan, 28-32.

24. Rasmun. Stres, Koping dan Adaptasi. Jakarta: CV. Sagung Seto;2004

25. Sabina, G., \& Bringiwati, B. 2016. Perempuan yang Berada di Lapas (Lembaga Pemasyarakatan) Perlu Mengembangkan Mekanisme Koping Efektif

26. Saryono, \& Anggraeni, M. D. 2017. Metodologi Penelitian Kualitatif dan Kuantitatif dalam bidang kesehatan. Yogyakarta: Nuha Medika.

27. Shuhaimi, N. F., Hamizi, S., \& Razali, S. 2018. Opinion on Support System For Mother in Prison : A Qualitative Study.

28. Stuart, G. W \& Sunden, SJ. Buku Saku Keperawatan, Edisi 5. Jakarta: ECG;2006

29. Siebrecht Vanhooren, Mia Leijssen \& Jessie Dezutter . Coping Strategies And Posstraumatic Growth;2018

30. Taylor, S, E. Health Psychology. $5^{\text {th }}$ edition. New York: McGraw-Hill, International Edition;2003(12)

31. Taylor, S, E. Health Psychology. $7^{\text {th }}$ edition. New York: McGraw-Hill, International Edition.2003(12)

32. Tiarani, N. Naskah Publikasi : Strategi Koping narapidana Seumur hidup. Surakarta: Program Studi Magister Psikologi Sekolah Pascasarjana Universitas Muhammadiyah.(7)

33. Undang-Undang Nomor 12 Tahun 1995 tentang Pemasyarakatan. 1995. Jakarta.

34. Viktoria, Venie. 2007. Narapidana Wanita: Stigma Sosial dan Kecemasan Untuk Kembali ke Masyarakat. Jurnal Psikologi Universitas Diponegoro, Vol 4, No. 1.

35. Waldani, J., Saam, Z dan Umari, T. 2017. The Influence of Group Guidance to Stress Levels of Women Inmates (Non Drug Cased) at Pekanbaru Children's Corretional Institution, 4(2), 1-12. 